Original Research Paper

\title{
Insights into the Impact of Implementing a Smart House on Special Needs People in the UAE
}

\author{
Ahmad Shubita \\ Software Engineering, University of Petra, Jordan
}

Article history

Received: 04-04-2019

Revised: 20-07-2019

Accepted: 24-10-2019

Email: ashubita0720@gmail.com

\begin{abstract}
One of the benefits of smart houses is empowering the special needs in their daily life. There is clear effort in helping special needs live independently yet it's not widely implemented in the UAE. This study aimed to give insight into the efforts of supporting their daily activities regarding health, security and time-efficiency. It investigated and identified the impact of implementing smart environments to overcome disabled people's struggles and obstacles in their ADLs. This research used three data collection techniques; survey, questionnaire and interview. Using these techniques, it's clear that smart homes are useful for special needs in many aspects. The main result of the research was its time efficient; but based on the task and experience. The privacy and security level(s) depend on the family and the individual's condition, it can serve their health needs per their health condition. The effects of smart homes might permanently change the living styles of special needs people in the Emirati culture.
\end{abstract}

Keywords: Smart House, Technology, Security, Special Needs, Disability, Emerging Technology

\section{Introduction}

A daily lifestyle is about working, being with family and friends, being able to finish responsibilities and living a simple life at home. However, that's talking about the public here. It's not the same for everyone; there is a small percentage of people that can't do even the simplest things by themselves. Nevertheless, some people and companies are giving the effort to break this barrier between the public and the special needs. This research showcases a method to help special needs using an emerging technology.

The best technology-related effort to help them is living in a smart house. A smart house is a house that primarily focuses on the integration of different services within a home environment by using a common communication system (Ni et al., 2015). It has a highly advanced, automated systems to control and monitor any function in the house, from lighting, control, security, windows, to door operations (Craven, 2016). Having a smart home entitles making any possible task in the house performed electronically to give the resident the most amount of comfort especially for people with certain disabilities and illnesses (Ni et al., 2015).

Based on an article about smart home technology, "Making homes "smart" is a growing trend that has gone from button-press security systems to controlling and observing your home from anywhere" (TSHT, 2016). In any country, there is a considerable number of disabled people with different problems and needs. According to Albayan News, the number of people with disabilities didn't even pass ten thousand people in 2007 (Alsanhousi, 2007). However, in another newspaper in 2015, a study shows that the number of physically challenged people doubled to around 22 thousand individuals ("Abilities" announces that 22 thousand is the number of disabled in the UAE, 2015). It means that they are continuously increasing and it is a sign that the country is doing its best to help and support them in every aspect of their life.

The UAE is one of the countries that is trying to support them in education, medical, working, but most importantly, lifestyle. In the UAE, houses are mostly traditional, two-story villas, with the standard technologies -like TV, Fridge, washing machine, vacuum cleaner, AC, etc.-. The problem with these devices is they are always not very usable for people with disabilities. Lately, a lot of companies are inventing solutions to help in some of these problems. Many people in foreign countries are starting to live in these houses.

Apparently, the UAE is one of the countries that are trying to implement smart homes. If that's the case, then why haven't there been cases where citizens are seen living in it? Could some problems prevent citizens from 
living in a smart house? Before, there was a lack of awareness in the society about smart technologies and how to apply these technologies and devices into their homes. Nowadays, people have more knowledge about technologies, since Dubai is slowly transforming into a smart city. Seeing as smart houses are an emerging technology that implements multiple systems and smart devices, are they also a solution to make the disabilities' lives easy? Do they provide the right facilities to satisfy their needs in their homes? Considering the UAE is an Islamic country, it's clear that privacy is a significant issue that need to be considered. If special needs were to live in smart homes, can their health be monitored from their rooms to promote independent living?

This research is aiming to investigate the impact of smart houses for special needs' people, to find out to what extent does an intelligent house help facilitate the daily needs of disabled people especially in security, health satisfaction and time-efficiency. Moreover, the study will have more insight about the possible obstacles and challenges in the process of adapting to live in a smart environment and the challenges that might have an impact on the special needs when living in smart homes with assistive technologies in the UAE.

This research will showcase a literature review that's about other research papers (state of art). After gaining a solid background, the data collection methods are discussed as well as the results for each method. The next section is discussing the findings based on the research questions and find the differences and similarities in them. The final part is the conclusion where the implications will be presented with some suggestions of the study.

\section{Research Questions}

\section{Is Living in a Smart House Private and Secure for Disabled People}

The aim is to know to what level is a smart home safe and secure for special needs, considering we're in an Islamic country that values personal privacy. To know if it's suitable and safe to let special needs' people live there with no worries of security issues. Also, to see whether being surrounded by cameras and sensors is considered a privacy breach or not. This question focuses on the privacy and security variables.

\section{How can Smart Houses Satisfy the Daily Needs of Special Needs in Health Care}

To see whether smart houses are the right solutions for special needs people and if it will make them independent and if it eases their daily needs in their lives. To see how possible it is to monitor their health conditions and whether there are suitable assistive devices available in a smart home. To have an insight about how can hospitals and health care institutions monitor their health without being hospitalized. This question seeks to find out the level of health satisfaction.

What are the Diverse Challenges Involved when Living in Smart Houses with Assistive Technologies

The aim in this question is to investigate the challenges in implementing a smart house in an Emirati environment and if it's appropriate for the disabled individuals. Also, to what level is building a smart house hard to implement and does it take a considerable amount of time to construct and build the house? The importance of this question is to get a general idea and to seek the challenges for disabled people in $\mathrm{SH}$.

Are Smart Houses Time-Efficient for Special Needs' ADL (Activities of a person's Daily Living)?

ADL covers a broad range of living functions in any house, like using the telephone, preparing meals and drinks, watching TV, going to sleep, wearing clothes and many other simple activities. The goal is to find out how much time does it take for special needs to finish common activities in a smart home. To see if smart houses support shortening the time to finish an activity, especially for people with disabilities.

\section{Background}

Smart House technology is, as defined by Bugeja et al. (2016), an A dwelling [home] incorporating a communication network that connects the key electrical appliances and services and permits them to be remotely controlled, monitored or accessed". As an emerging technology, there are a lot of researches done to serve a smart house area. For example, activity, detection and recognition in home environments has been recognized as a fundamental research area, as (Melkas, 2013) said. An important detail to take note of is the types of activities in a person's daily living (ADL), especially for disabled people and older people at their homes to support their independent living (Melkas, 2013).

According to (Hong et al., 2012), ADL covers a broad range of living functions in any house, be it normal or smart. Activities like using the telephone, preparing meals and drinks, washing the dishes, taking baths and showers, wearing clothes, taking medications, toileting and many other simple activities. To do these activities, a previous research done by Corralejo and Nicolás (2014), they experimented on fifteen participants with different motor and cognitive impairments. The experiment was to let them interact with assistive applications and menus using assistive Brain-Computer Interface (BCI) tools.

The participants were asked to select items across different lists in several devices used in the study. It included Television (TV) to switch on/off, volume control, switch TV channels. The control to lights to switch on/off, change the light color, turn up/ down the 
light intensity. They experimented on the heater and fan controls to Switch on/off, turn up/down power or speed strength. There was also a phone to see how they'll pick up or hang up the phone, dial a phone number, or automatically dial the emergency phone number (Corralejo and Nicolás, 2014).

Besides, it's important to do research about the assistive technologies correlating to the needs of people with disabilities because their needs are different from "the general population and the groups typically investigated in human-computer interaction studies" (Derniris et al., 2013). Since smart houses serve a whole variety of people, we need to focus on one group of them and see what they require and how can we help them using assistive technologies. Also, the reason of having a smart home is "not to replace experiences that we already enjoy today with our families, but to support or enhance experiences you already enjoy... but in new ways" (Wilson et al., 2015). However, we cannot forget the concerns involved in living is a smart house and the challenges that differ according to the people living in such houses, be it individual or with families. These studies and previous researchers provide insight in three main areas: Privacy and Security, Health and Wellness and Challenges and Obstacles, especially to special needs people.

\section{Security and Privacy}

As a result of numerous security breaches, smart home system has to be protected against intrusion and has to make sure that the information reaches only to the right people (Portet et al., 2013). As mentioned before, to cover the many functions in the house, there has to be a variety of sensing technologies are available, such as cameras, audio devices and statechange sensors fire guard and smart door guard (Hong et al., 2012; Melkas, 2013).

Since security is involved in smart houses, there are several papers done to discuss this matter and it's shown to be contradictive. First of all, a lot of research projects were done in Sweden, France and the US that involved using sensors and assistive technologies to assist either older people with mobility impairments and cognitive disabilities (Derniris et al., 2013). As for their experiment, they aimed to evaluate an actual "smart house", with an in-home monitoring system and sensors, to several residents for six months. Results show that the residents expressed overall positive perceptions of the sensor technologies and did not feel that these interfered with their daily activities. Besides, especially for older people and disabled individuals, they have needs that include an easy accessibility contact for emergency help, assistance with hearing or visual impairments and automatic systems to detect and prevent falls (Wilson et al., 2015).
The contradiction is evident in another interview; where all 18 participants expressed that many smart houses consider monitoring systems and video cameras as a primary sensor. At the same time, they felt that it invaded their privacy and felt they were being watched (Portet et al., 2013; Morris et al., 2014). However, these forms of technology were thought to increase safety and security around the home. In a systematic literature review, many participants felt that smart technologies may help to improve their independence. While it was not formally addressed in the identified studies, it is possible that improvements in safety, security and independence may also have a positive effect on quality of life (Morris et al., 2014).

Many studies and papers show huge concerns about security in living in smart homes. These studies included interviews, surveys and systematic literature review. Results indicate that many participants were reluctant to introduce sensing technologies and recording devices into their home. They felt wary of leaving digital trails others can monitor and use to their advantage, such as to break in when the house is empty (Ali et al., 2017; Portet et al., 2013; Wilson et al., 2015; Derniris et al., 2013)

\section{Health and Wellness}

Moving on, the health of older people typically weakens with increasing age. It leads to greater demand and interest for long-term care and support from the government and relatives to be able to promote independent living and safety life (Labonnote and Høyland, 2015; Morris et al., 2014). Moreover, smart home technologies can sometimes enable people, like senior citizens and those with disabilities, to live in their home rather than being hospitalized. Also, their aim is usually to perform functions without disturbing the user and without causing any pain, inconvenience or movement restrictions (Morris et al., 2014).

Furthermore, there's an apparent effort to promote healthy smart home concept which offers a variety of services like automated blind control to avoid painful movement, monitor the health status to predict dangerous situations, to recognize subtle changes in their activities and behavior. Also, scientists are trying to make health-oriented systems that oversee the status of the person like logical distress signs, movement detector, video feeds, etc. (Portet et al., 2013).

It is critical for a healthy smart house to have technologies to be fully functional to fulfill its roles to monitor the person's health as a mean of a continuous collaborative relationship between patients and healthcare providers (Labonnote and Høyland, 2015). Moreover, it's important to be able to measure health status and detect emergency situations correctly. There should be 
sensors to detect motions, a stove temperature sensor -in case it has been left on- and bed sensors that can detect the presence, respiration, pulse and movement in the bed. These sensors especially are crucial because it can also monitor sleep to identify sleep stages to detect early development of diseases like dementia and Alzheimer.

Adding to that, many research and studies that indicate the importance of monitoring patients in their homes and how it's beneficial to them instead of getting admitted to the hospitals. Besides, there are monitors that generate alerts according to the patient's blood pressure, oxygen saturation, body temperature and heart rate monitoring. Especially for people with heart and chronic diseases (Lesende et al., 2013; Derniris et al., 2013; Hong et al., 2012).

\section{Challenges and Obstacles}

Additionally, no matter how advanced and efficient a smart house can be, it is not perfect. Based on previous studies, many challenges and concerns are evolving around the technologies and capabilities of smart homes. The most obvious obstacle for a smart house is technology. To older people, their primary challenge is the possibility to be able to use the said technologies like iPad (Alvseike and Brønnick, 2012). Moreover, according to the results of a study done by Derniris et al., 2013), the study's nine participants expressed a few concerns which guided the research team to make changes.

Also, smart houses usually include active sensors, monitoring systems and electronic aids their primary goal is to help older people and disabled people to live independently at their home. The problem, however, even if the house system is easy to use or durable, some visually, physically and cognitively impaired people might find it hard and challenging to access equipment and to use switches and controls. Adding to that, many claim that smart devices and sensors are error-free. However, in a user evaluation of 8 people from 71 to 88 years showed that when one resident did not have bed sensor readings through the night, an interview revealed she spent the night sleeping in her favorite chair (Derniris et al., 2013). Also, another study indicates that "there is considerable uncertainty in the "sleeping" recognition defined this way since the user may trigger the sensors while sleeping but also while sitting on the bed" (Ni et al., 2015). It only means that sensors might not differentiate between sitting, lying down, or sleeping.

Adding to that, smart homes are considered new and different than what we've seen before. In a study to provide insight into impacts, decisions and options in technologies that are used by municipalities to improve productivity in elderly care services, they've introduced over 60 assistive devices and experimented it on several participants (Melkas, 2013). During their observation, they've seen that some devices disregarded the participants' health conditions and experiences, some residents weren't able used to some devices as they wanted it to work. Because of such results, there was little effort to pay attention to small details to such issues that resulted in not bringing the desired positive impact.

This shows that there isn't many research and development about a useful application in a comprehensive manner (Melkas, 2013; Lesende et al., 2013). Therefore, to address these and other challenges, smart home applications have to be evaluated on an ongoing basis and have to include end-users in all stages of the study, experiment, or workshops (Melkas, 2013). Based on these studies, it's clear that the success of smart homes lies on the impact which helps and empowers special needs' people and elders. Likewise, according to such studies, there is much work still needs to be done in addressing the potential end-users' needs and expectations and working on the negative technology-related factors (Derniris et al., 2013; Alvseike and Brønnick, 2012).

\section{Summary}

After reviewing many studies, articles and journals discussing smart homes in different areas, there are several highlights to what was agreed in most studies. Firstly, all studies showed that in general, smart homes are a great technology for many reasons. The most important reason is how helpful it is to assist elders and special needs' people and how to be able to facilitate their daily lives as much as possible. Relating it to the UAE, it is also becoming trendy and some companies started showcasing their ideas in the country because of the rise of senior citizens and special needs.

Secondly, most researchers have a contradictive view about the security and privacy. Some convey that smart houses are considered as invading of privacy because of the monitoring systems, cameras and sensors. On the other side, some said that it doesn't invade their privacy and it's, in fact, helping them keep the house secure, safe and private. Especially if we're talking about an Islamic country, the UAE is very strict when it comes to privacy and personal security. Some sensitive issues include putting cameras inside, not outside the house. If the gender of the resident is female, they might be very reluctant because one might think it's right to have cameras in case of emergencies or accidents. Some might think it's invading their daily life activities.

Thirdly, talking about how smart houses affect people's health; especially if they are with health problems. Some studies about smart homes and health illustrate that governments, health facilities and health care institutions are trying to promote a healthy, smart 
home concept by giving them the opportunity to try living in a smart house, either alone or with someone, instead of being in the hospital all day. In the UAE, it's becoming a trend to bring home nurses or providing health services at home like bathing, checking the medical condition and recording sensitive and vital information. Therefore, having a smart home with supplied equipment and devices is a great way to allow to learn how to be independent and promoting an almost normal life, especially for young special needs' individuals.

Lastly, all these reviewed studies indicate that smart homes are not perfect. They are not error-free as some studies show. The obvious obstacle is the technology itself. Since we're talking about a particular niche and not the general, young public, not everyone has the same abilities. Special needs and older people are bound to face problems because they' might not know some devices well and might find it hard to access some equipment, switches and controls. And residents in the UAE might have a huge possibility of facing this problem because of the language barrier. Since most devices are in English, Arabic elders may not be able to read such technical words. Another possible problem is with implementing smart devices into Emirati houses which are built using cement and bricks. That means that it will be hard and expensive to modify the walls according to the device.

Based on the above, there are a lot of effort to help elder people and special needs to live life independently and make their life easier. However, we've seen that all researches are in foreign countries and many are focusing on elder people and not special needs or disabled people. This study will research about the impact of implementing smart homes to special needs' specifically in the UAE society.

\section{Methodology}

To collect the needed information, several data collection methods were used to collect qualitative and quantitative data to help gain information about the research. The first method used is publishing an online Survey. A survey is defined as asking questions to measure of opinions or experiences of a group of people (SMSQ, 2014). This method is useful for the research to know the opinion of a sample of 35 individuals from the public who don't have disabilities. It will be distributed randomly via sending the link to know their opinions about implementing a smart house and how it can affect their daily lives. The questions asked were closed questions to prevent getting the person answering bored and lost. Most of the questions focused on getting a general view of the disabled's needs and how the public view their daily needs. There were questions to describe some possible challenges that may face the special needs and some about time health satisfaction as well as privacy and security. Therefore, the survey highlighted all variables in the research questions.

The second methods used is distributing paper questionnaires. Even though surveys and questionnaire are somewhat similar, questionnaires are typically a set of printed questions with the purpose getting answers from different prospective and point of views (Rogers, 2016). The papers were distributed to a group of 10 parents. All the participants were female mothers with a higher level of education with one or more children. This group was chosen because of the need to gain insight about the disabled people from the prospective of mothers who care for the benefit of their children. The questions asked in this questionnaire are asked to come from the prospective of mothers who have a general idea of the needs of their children.

The third data collection method is doing an interview. According to Farooq, an interview is the process of having a conversation via a communication method, like the telephone or face-to-face, to discuss some purposeful topic (Farooq, 2013). The interview was with someone from Al-Thiqah Club for Handicapped in Sharjah. The interviewee is a specialist who has been dealing with special needs who frequently visit the club for many years. What was special about this method is that the person interviewed was handicapped as well, so it's was beneficial for the research because it gained insight from the prospective of a special needs and specialist. The reason for choosing to do an interview is to collect information about their situation and gain insight about their lifestyle in their home. The questions asked by the interviewer were based on the four research questions and most questions were open-ended to gain the most amount of information and to allow the other person the freedom to express their opinion.

\section{Results}

After collecting data from various methods, the results are separated per the research questions. Each question has one or two variables it focused on and the questions asked were based on these variables. The data collection methods were used to ask the questions about most variables.

\section{Research Question 1}

The first question is about the privacy and security of living in smart homes for special needs. All the participants were female mothers with a higher level of education with one or more children. In the questionnaire, there was a question about whether privacy will be an issue in living in smart homes with their children in the UAE considering the Emirati culture. Figure 1 show that $64 \%$ of the responses agree about living in a smart home with their family. 


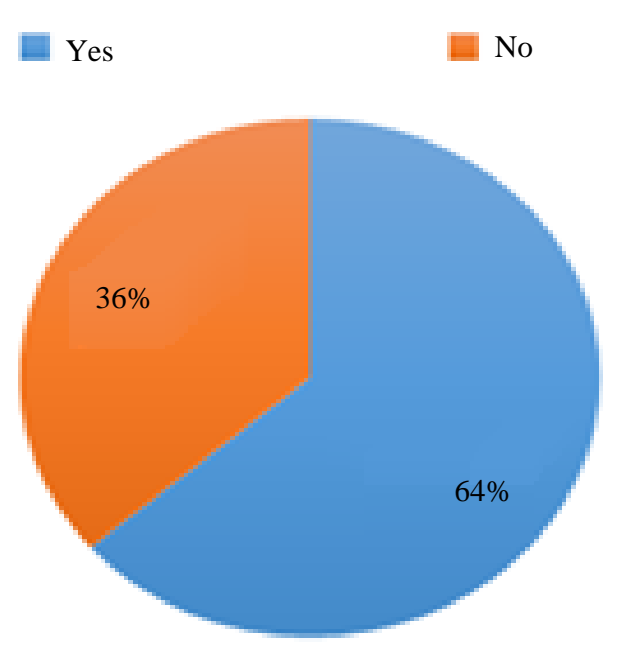

Fig. 1: What do you think about living in a smart house with your child?

It's a breach of personal space

It's a safety measurement

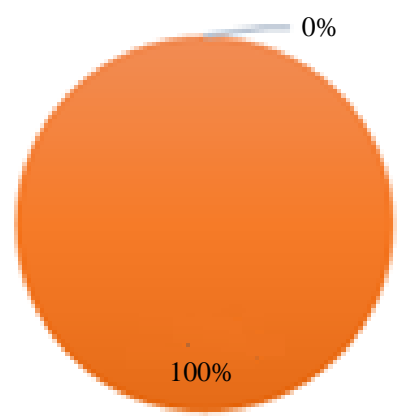

Fig. 2: What do you think about having sensors in the disabled person's bedroom

Another question was to see their point of view in having sensors in the special needs' bedroom. 100\% of the respondents stated that it's a safety measurement rather that a personal space breach (Fig. 2). The same question was asked in the questionnaire and the responses are like that in the online survey.

In the online survey, there was a question about having cameras to monitor the disabled's daily activities for some Emirati families. The responses are a mixture of opinions whether it's a privacy concern or not (Fig. 3).

In the interview which done with a specialist who has been dealing with special needs who frequently visit the Handicapped club for many years, there were questions about living in a smart house and it its considered private in an Emirati country. She stated that sensors should be provided for special needs people only and cameras can be spread around the house, so the person won't feel insecure and sensitive about the placement of the cameras.

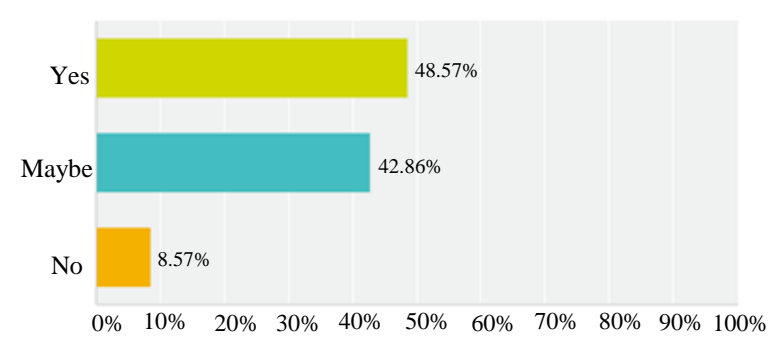

Fig. 3: Is it a privacy concern to have cameras to monitor a disabled's daily activity for some Emirati families

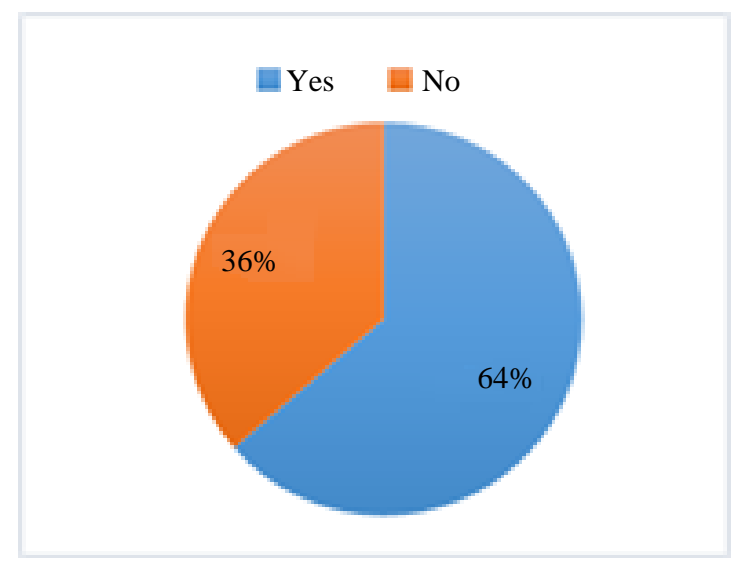

Fig. 4: Do you think it's an effective way of monitoring the person's health without being hospitalized

Also, the cameras could be placed near the doorway of the special needs' room. The reason is because adding cameras around his/her personal room would create a barrier because there are personal activities that the person doesn't want anyone to see like after taking a shower or a place to change.

Moreover, the access to the camera should be monitored by one or two people very close and personal with the handicapped. However, there are some cases that cameras can be allowed in the room like people with autism, old people, or disabled children that stay with maids. In general, the goal is to facilitate and respect the privacy of the disabled individual.

\section{Research Question 2}

The second research question focused on the health satisfaction variable where it discussed how to take care of special needs in their homes and to what level should they be satisfied. All the participants were female mothers with a higher level of education with one or more children. Therefore, in the questionnaire, a question was about whether the respondents see smart homes as an effective way of monitoring the person's health without being hospitalized and not all answers were the same (Fig. 4). 


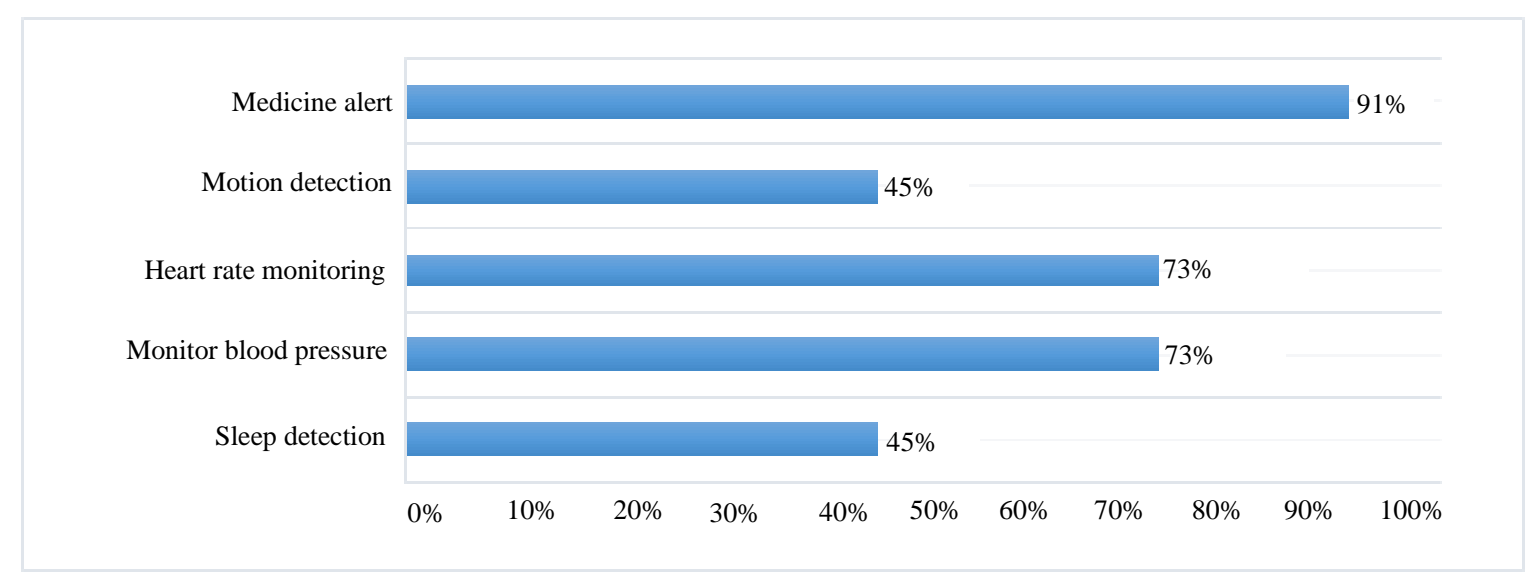

Fig. 5: What are the things to monitor in a person's health condition

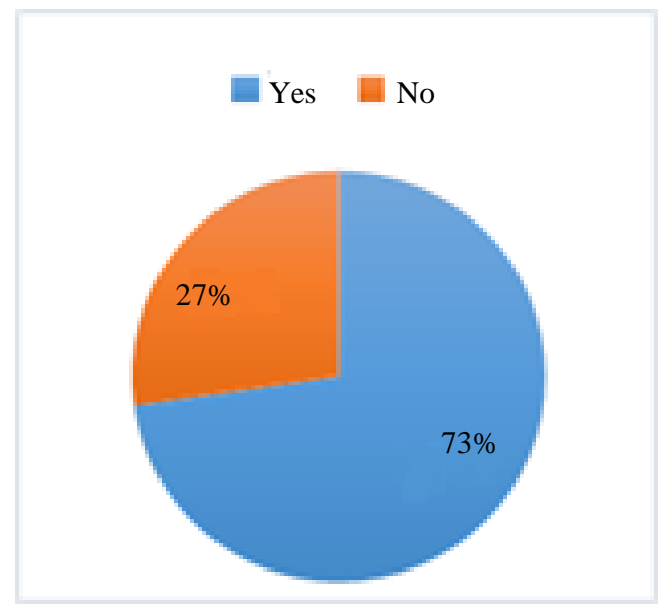

Fig. 6: Will you trust leaving your special needs' relative in his/her room by his/herself to promote independent living

Another question regarding the health satisfaction variable in the paper questionnaire involved what the things are to monitor in a person's health. Figure 5, all the responses differ on the five given choices with having a reminder for taking medicines received the highest percent of answers.

As for the online survey which done on a sample of 35 individuals from the public with no disabilities, there was a question about whether living in a smart home makes the person's living comfortable or not. Most answers agreed that it does make it comfortable and easy.

As of the interview, there were questions regarding the health care variable and whether smart homes can satisfy the possible needs of special needs. According to the specialist, there are some important devices (or sensors) that need to be provided by the builders like smart door guard, fall prevention sensors, medication alert and light control sensors. If such devices weren't available in the smart homes, it could lead to the possible need of a helping person. That's why, having smart devices promote independent living.

Adding to that, she talked about monitoring the person's health conditions at home. She said that beds should be medical; that causes alerts when the body temperature is high/low, or the heartbeats are high/low, or when they are injured or hurt, because the person's ability to compresence such situations are hard for their mind. Talking more about the ability to be independent, the house needs to be specifically designed for them like the floor type and the placing of the items and furniture.

\section{Research Question 3}

The third research question is about the challenges that face special needs in smart homes. According to previous research, one of the main challenges is allowing the person to live independently. In the questionnaire, there's a question directed to this challenge to know who much the respondents trust their special need's relative to be in his/her room or house to promote independent living. $73 \%$ believe that it's a fine to leave them alone yet there were some parents who didn't agree with them, as seen in Fig. 6.

As for the online survey, there were asked about the challenges special needs' might face when they'll live in a smart home. Accordingly, as they were given several choices to choose from, most people chose challenges like the devices' language and it being a new technology as the most common challenges they might face. On the other hand, it seems that monitoring the disabled's health is not much of a challenge when living in smart homes (Fig. 7).

The same question was asked in the interview about what challenges need to be considered. The difference in this question was it being open. The findings show that age and the type of disability makes a difference when living in 
a smart home. For example, people with mental disabilities have a different mental age than their actual age. So, their needs are different because like they like to play, move a lot in the house so the place need to have suitable space, catching colors like green. People with impaired mobility need to take their height and muscle strength into consideration. Another challenge was the washroom; where the basins and the $\mathrm{WC}$ need to be in a similar height as the disabled. Moreover, the technology is somewhat a problem because it needs to be suitable for the mentally challenged (easy to understand) and to be able to use the devices.

\section{Research Question 4}

The last research question is to see if smart homes are time-efficient, especially for special needs. In the questionnaire, the participants were asked if they think that when living in a smart environment, the time to do daily activities, like going to bed or closing lights and doors, are reduced or not. Based on the answers. Most people said it will reduce time by more than two-thirds, yet $27 \%$ stated that it can make the task complicated rather than simple (Fig. 8).

In the online survey, people were asked a similar question to the questionnaire and $88 \%$ of the answers were that 'yes it will reduce time". Based on their answer in the previous questions, they were given several ADLs and were requested to order them from the fastest to the slowest. Per answers, around 25 per cent chose answering the telephone as the fastest task, with going to sleep the second fastest task with 22 per cent. On the other side, it seems like taking medicines takes the most amount of time (Fig. 9 and 10).

In the interview, the specialist discussed how some devices could reduce time. However, this factor is affected by the type of the disability and the task. For example, a task like getting up from the

Bed needs to take the space and height into consideration for easy movement. For blind people, the room must not be full of items to allow faster and more efficient movement. For motor impairment, the washroom must be spacious and facilitated with the right equipment and sensors to finish the task as quick as possible. Another question asked during the interview is how the medications should be taken and how much time does it take to finish taking the needed medicines and daily check-ups. For example, there should be alerts to alarm the person to take their medication with no mistakes on what to take or not.

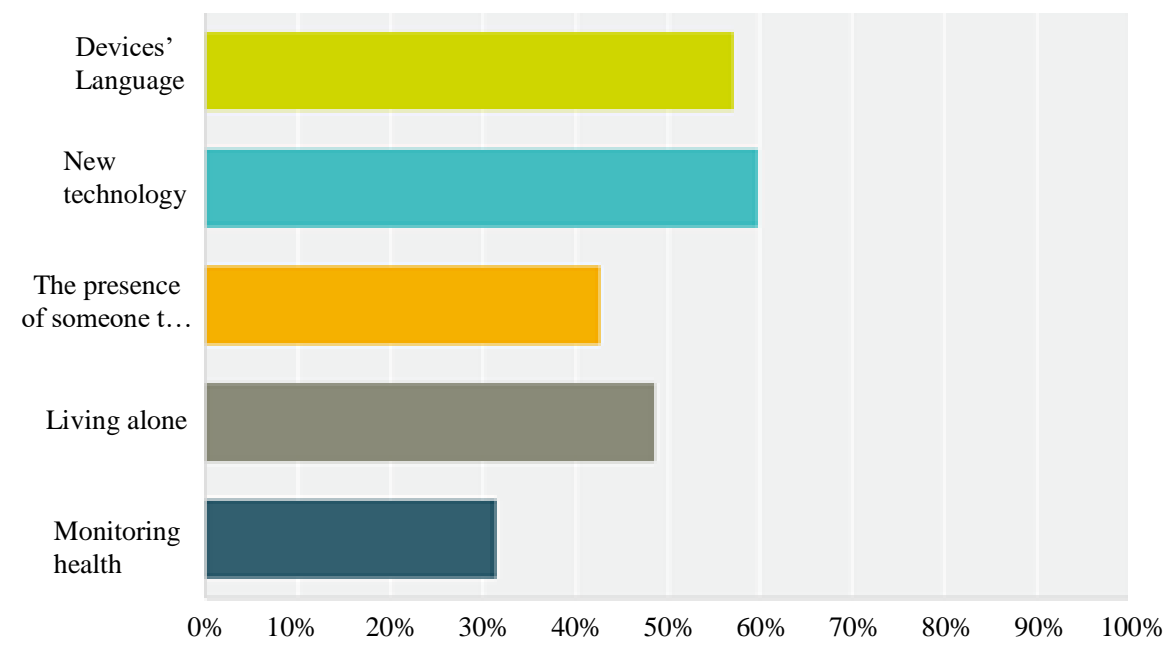

Fig. 7: What are the challenges in living in a smart house

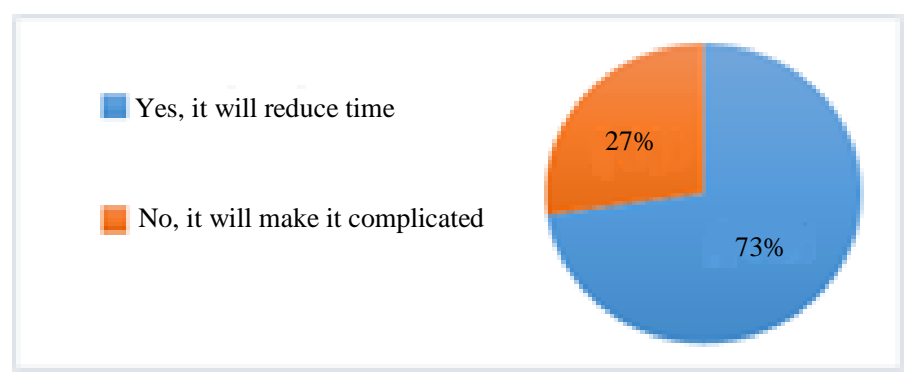

Fig. 8: When living in a smart environment, do you think it will reduce the time to do daily activities 


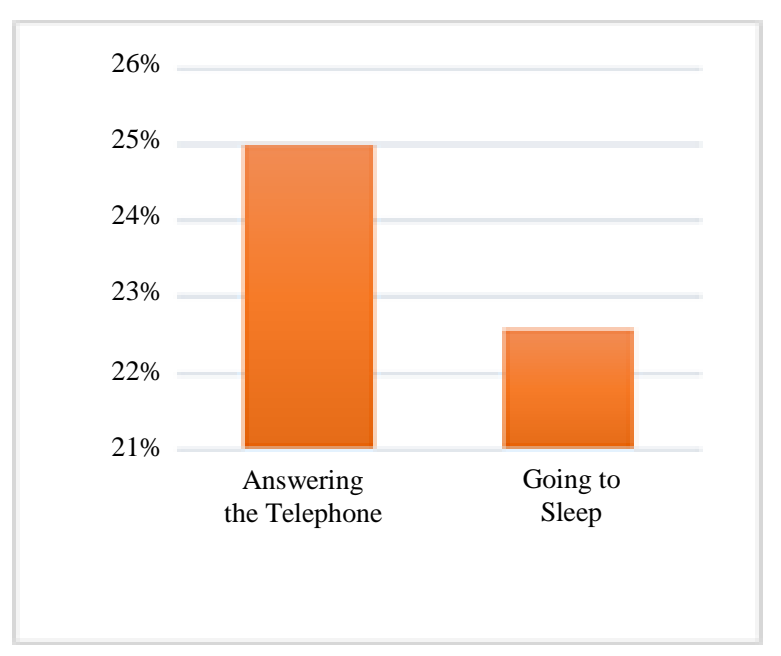

Fig. 9: The fastest task according to the time to finish it

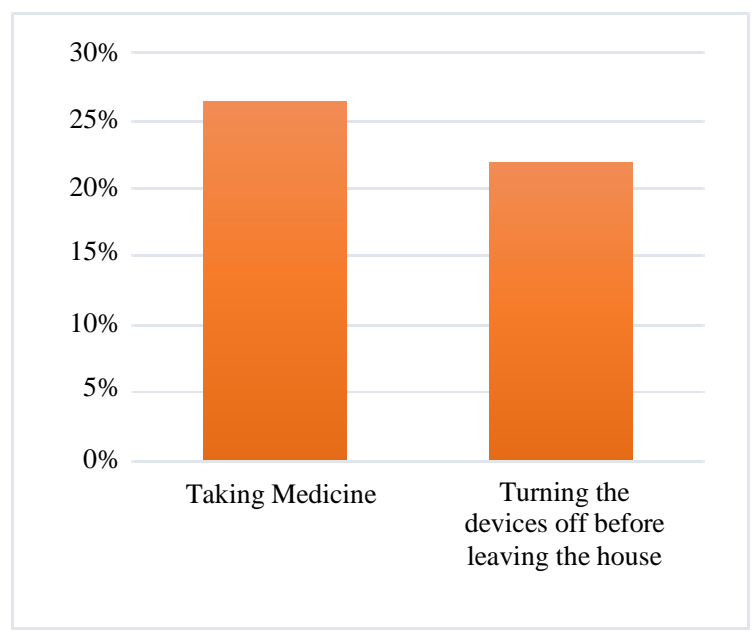

Fig. 10: The Slowest task according to the time to finish it

\section{Discussion}

Based on the findings of the data finding techniques, below are the discussion and analysis of the results of all the methods based on each research question.

\section{Research Question 1}

Based on the findings in all methods, all participants state that having cameras in the house is a privacy concern. To be more specific, in the paper questionnaire where all participants were female mothers with a higher level of education with one or more children stated their opinions, more than half of the parents agreed that having cameras in the house is a privacy concern, even though most of the parents agreed on living in smart homes with their special needs' children or relatives. This means that, they are accepting the concept of living in a smart environment even when being surrounded by it because they all agreed that having sensors in the disabled person's bedroom is a safety measurement. On the other hand, while having sensors is fine with the parents and public, they are concerned about having cameras around the house even when it's for the purpose of monitoring the disabled person.

To support this statement, based on the interview conducted with a specialist who has been dealing with special needs who frequently visit the Handicapped club for many years, the specialist tried to balance the limit of being monitored and avoid it from being a breach of privacy. Based on her experience, it's recommended to distribute the cameras all around the house and place the sensors in the disabled person's room. The reason for having cameras everywhere is to avoid making the person feel insecure and sensitive about the placement of the cameras.

Her other suggestion is to place the cameras near the doorway of the special needs' person because adding cameras around his/her personal room would create a barrier. That's because there are personal activities that the person doesn't want anyone to see like when after taking a shower and need a place to change. As mentioned before, the disabled can be emotionally sensitive, so the best solution is to allow access and monitoring of cameras by one or two people very close and personal with him/her.

On the side note, she stated that some cases need to have cameras in their rooms for individuals like old people, children that stay with maids and people with autism. Also, some parents mentioned that it's a good solution because they can see their baby's location and whereabouts.

After researching about this concern, it seems that when it comes to security and privacy, the UAE is one of the countries that have contradicting opinions about having monitoring devices in their homes. Each family will take the suitable procedures that will benefit their children and family the most. For example, if the family thinks that having cameras and sensors will bring more safety and protection for them and their special needs individual, they will not be reluctant to place such devices in their home. Nevertheless, if they think that it will invade their privacy and it will attack their vulnerabilities, it will cause insecurity problems and uncomfortableness, be it for the disabled or not.

\section{Research Question 2}

According to all the answers in the methods, most parents agreed that living is a smart house is an effective way of monitoring the person's health, especially if it will avoid the person being hospitalized frequently rather than being with their family. This indicates that they dislike the idea of frequently going to the hospital with their children or close relatives to do regular check-ups 
that they can do in at home if the right devices and facilities were available. In the questionnaire, such devices include medication alerts, based on what most parents confirmed as well, heart-rate monitoring and BP monitors and it's because of the importance of what these three medical devices provide.

To some families, constantly going to the hospital could be a problem even for the simplest check-ups. So, the idea of implementing similar devices in their home will be beneficial for them as well as the special needs' individual(s). This will be done by providing most of the devices that the respondents selected in the questionnaire as well as other devices like smart door guard, fall prevention sensors, medication alerts and light control sensors, as mentioned by the specialist. The interesting thing is that there were two methods that had medication alert as a necessary device, this shows that reminding the person of his/her medicine intake is very important. If these devices were available in smart homes, it will not only decrease the number of hospital check-up and visits, it will also efficiently affect their lifestyle and promote independent living. It will the disabled person to know his/her way around without the need of someone to help and assist them.

The specialist noted an important point. The smart house must be provided with a medical bed that causes alerts when the body temperature decreases or increases, or when the heartbeats are instable -such information are received by the bed sensors-, because sometimes, for some cases or illnesses, individuals lose the ability to recognize similar signs and the ability to act like a normal person. Also, special needs have different body healing capabilities. For example, people with motor impairment and diabetes have a slower body cycle and take more time to heal (e.g., a small bruise takes 2-3 days to heal for a normal body, but it takes much longer for a special needs' body).

According to the data received by the participants and the specialist, the family that will live in a smart home must make sure that the builders and contractors and the smart home solution company must design the house and the room layout according to their special needs' child or relative preferences. The beds and floorings, for instance, must accommodate the disabled's medical needs to fully satisfy their health condition, especially for people with diseases like diabetes and chronic diseases.

\section{Research Question 3}

This question was asked to identify the possible challenges that could face the special needs' when he/she will live in a smart home. In the past, there was a challenge about allowing the disabled to stay alone in the house or room. Accordingly, the same challenge was asked to find out if it's a challenge in the UAE or not.
Based on the parents' opinion, they mostly believe that they can leave their special needs' relative alone to promote independent living. Yet some parents expressed their opinion about disliking this idea because to this day, people don't fully trust technological devices, so some devices can damage or send false alarm to the parent(s) and they might need to have someone around to stay with their disabled relative/child.

Per the answers in the online survey, the sample of 35 individuals from the public with no disabilities, selected the most possible challenges when living in a smart house. The most amount of responses stated that the technology being new and modern is the number one challenge, followed by the device's language. The reason behind this result is most devices' main language is English. Many Emirati families and parents may not fully understand English which could lead to choosing wrong selection(s), or even damaging the whole house system. On the other hand, monitoring the person's health condition is not much of a challenge because one of the smart houses' goal is to provide the right assistive technology to provide health care.

Moving on, the specialist stated that the type of disability and age makes a difference when living in a smart home. This statement is supported by the survey where the public were asked whether age makes a difference when living in smart homes and $85 \%$ responded that it does make a difference. For example, people with mental disabilities have a different mental age than their actual age. Therefore, the house must accommodate their playful self, the space to move, the colors for the devices, furniture and colorful tiles as a guide.

Somehow, the technology itself will be a problem for the mentally challenged. It needs to be designed to be easily handled and simple to understand. On the other hand, it won't be a problem for individuals with motor disabilities. For them, the heights and muscle strength need to be taken into consideration. Another challenge was the floorings of the smart house where it needs to be easy to slide, hard to slip and easy to move from one place to another.

What was concluded from this question is that there will be challenges no matter what but there are efforts and methods to try overcoming some challenges. That depends on knowing the needs of the disabled person who will live in the smart home and add and place the devices according to their requirements and necessities.

\section{Research Question 4}

This question is important to consider seeing if smart homes can be time-efficient or not. Based on some ADL activities like going to bed, closing the lights and doors, it will ultimately reduce time and $73 \%$ of the parents and $88 \%$ of the survey respondents agreed that living in 
smart homes will reduce time for special needs. Moreover, there were some ADL activities listed and were ordered according to the time it might take to complete. The fastest activity to finish was answering the phone and going to sleep as the second fastest task to finish. The task that will take the most amount of time is taking medicines. On the contrary, the specialist selected this activity as the fastest because there are medicine alerts in the house that will notify the patient of the medicines they must take.

The specialist, however, stated that time could also differ based on the disabled's abilities and the task to complete. Some tasks need to take space and height factors into consideration for easy movement. Also, the room must not be crowded and full of items to allow fast and effective movements. As for people with motor impairment, tasks that involve the washroom could take some time to finish for them. Therefore, the washroom must be spacious and facilitated with the right equipment and sensors to finish the task as quick as possible.

The conclusion for this question is that time is a variable that changes per the task at hand. There are many ADLs that need to be assessed and the person's abilities as well. Another thing to note is the experience, where people who've recently moved in the smart home will take more time to get used to the devices and equipment than the individuals that have lived in smart environments for some time.

\section{Conclusion}

In the last couple of years, Dubai is becoming a smart city with all its smart services. Smart services like smart government, smart education and most importantly, smart homes. The main reason for developing all these services is to serve all types of people, especially special needs. That's why, there's a lot of effort to help special needs by having them live in smart homes. Based on previous research, smart homes are perceived as a method in helping the disabled and old people, especially as its considered as an emerging technology. To have an insight about smart homes for special needs, this research was conducted for this purpose and how it can serve their daily lifestyle in the UAE.

The research questions asked to gain insight about this topic focused on security and privacy when living in a smart house for the disabled, how can smart house satisfy the daily needs of special needs in health care. Also, what are the possible challenges when living in a smart environment with assistive technology and finally to see if smart homes are time efficient when doing ADL. To gain the accurate data, three methods were conducted; online survey, paper questionnaire and interview. The findings show that the family will take the right procedures to keep their family's affairs private per the disabled's needs. Also, to fully satisfy their needs, the house must accommodate the individual's health condition. Also, there will be challenges no matter what but there are efforts and methods to try overcoming some challenges that might face the disabled. Finally, time can differ based on the activity and the amount of experience when living in a smart environment.

In the end, after this research, many opportunities shall open because its giving a slight insight about several aspects in living in a smart house, especially when talking about living in an Emirati environment where the concept of living smart is new and modern.

\section{Ethics}

This article is original and contains unpublished material. The corresponding author confirms that all of the other authors have read and approved the manuscript and no ethical issues involved.

\section{References}

"Abilities" announces that 22 thousand is the number of disabled in the UAE. 2015. Emaratalyoum.

Ali, W., G. Dustgeer, M. Awais and M.A. Shah, 2017. IoT based smart home: Security challenges, security requirements and solutions. Proceedings of the 23rd International Conference on Automation and Computing, Sept. 7-8, IEEE Xplore Press, Huddersfield, UK. DOI: $10.23919 / \mathrm{IC}$ onAC.2017.8082057

Alsanhousi, A., 2007. The number of disabled in the country doesn't pass 10 thousand individual. Albayan.

Alvseike, H. and K. Brønnick, 2012. Feasibility of the iPad as a hub for smart house technology in the elderly. J. Multidisciplinary Health, 5: 299-306. DOI: 10.2147/JMDH.S35344

Bugeja, J., A. Jacobsson and P. Davidsson, 2016. On privacy and security challenges in smart connected homes. Proceedings of the European Intelligence and Security Informatics Conference, Aug. 17-19, IEEE Xplore Press, Uppsala, pp: 172-175. DOI: 10.1109/EISIC.2016.044

Corralejo, R. and L.A. Nicolás, 2014. A P300-based brain-computer interface aimed at operating electronic devices at home for severely disabled people. Medical Biol. Eng. Comput., 52: 861-872. DOI: $10.1007 / \mathrm{s} 11517-014-1191-5$.

Craven, J., 2016. What is a smart house? What is domotics?

Derniris, G., D.P. Oliver and G. Dickey, 2013. Findings from a participatory evaluation of a smart home application for older adults. Technol. Health Care, 16: 111-118. 
Farooq, U., 2013. What is interview method, definition and objectives.

Hong, X., C.D. Nugent and S. Martin, 2012. Dynamic similarity-based activity detection and recognition within smart homes. Int. J. Perv. Comput. Commun.

Labonnote, N. and K. Høyland, 2015. Smart home technologies that support independent living. Intell. Build. Int. DOI: 10.1080/17508975.2015.1048767

Lesende, I.M., A. Bilbao and I. Vergara, 2013. Impact of telemonitoring home care patients with heart failure or chronic lung disease from primary care on healthcare resource use (the TELBIL study randomised controlled trial). BMC Health Services Res.

Melkas, H., 2013. Innovative assistive technology in Finnish public elderly-care services. Work, 46: 77-91. DOI: 10.3233/WOR-2012-1470

Morris, M.E., B. Adair and K. Miller, 2014. Smart-home technologies to assist older people to live well at home. J. Ag. Sci. DOI: 10.4172/2329-8847.1000101
Ni, N., A.B. Hernando and I.P. Cruz, 2015. The elderly's independent living in smart homes. Sensors, Basel, Switzerland.

Portet, F., M. Vacher and C. Golanski, 2013. Design and evaluation of a smart home voice interface for the elderly: Acceptability and objection aspects. Personal Ubiquitous Comput., 17: 127-144. DOI: 10.1007/s00779-011-0470-5

Rogers, C., 2016. What is the difference between questionnaire and survey.

SMSQ, 2014. http://fluidsurveys.com/university/solvingmystery-survey-questionnaire/

TSHT, 2016. Trends in smart home technology.

Wilson, C., T. Hargreaves and R.B. Hauxwell, 2015. Smart homes and their users. Personal and Ubiquitous Computing, 19: 463-476.

DOI: $10.1007 / \mathrm{s} 00779-014-0813-0$ 